\title{
Con respetuosa contundencia, hablando en galego, sin cátedra, para los que quisieran hacer camino con él...
}

\author{
Aida TERRÓN BAÑUELOS \\ Universidad de Oviedo
}

Suelo regañar a mis alumnos por las barboteantes expresiones que, con frecuencia, utilizan en sus trabajos académicos al intentar reexponer el sentido de los textos que leen. $Y$, tras obligarles a rehacer las frases más confusas y obscuras, acabo haciéndoles partícipes de un secreto muy simple, que formulo en estos términos: "aquello que, tras leerlo, os resulte nítido, preciso, riguroso e inspirador - tanto que incluso consiga emocionaros- no lo toquéis. Reproducidlo sin más. Dejad que mantenga su brillo". Este consejo, profundamente antinarcisista, suelo aplicármelo a mi misma. ¿Quién renunciaría a robar las más bellas palabras escritas sobre ese Herminio profesor que muchos tuvimos el honor de conocer y tratar? Palabras que, escritas por uno de sus alumnos (Rafael Ojea), circulan a través de las redes, esparciendo, entre quienes tengan la fortuna de encontrarlas, la más genuina esencia del hombre: "Herminio conocía y cuidaba como un padre nuestra limpia mirada adolescente, fascinada por la letanía suave con que pronunciaba la palabra libertad. Con él impregnamos las piedras de Santiago de promesas y solidaridad y fuimos, por un momento, sabios. Con él sentimos discurrir admirados la filosofía de Marx explosionando en la radical humanidad de su magisterio y supimos, ya para siempre, que era la hora de que nuestro pensamiento ayudase a transformar el mundo. $Y$ si alguna vez quisimos ser educadores, quisimos ser él, sin fisuras: hacernos con el privilegio de la palabra que acaricia y produce la paz esencial del espíritu y el anhelo profundo del conocimiento y el compromiso".

"Con él sentimos discurrir admirados la filosofía de Marx". Eso decían. Y aunque hoy los tiempos no estén para estas líricas, sólo hay que dar tiempo al tiempo: tendremos necesidad de volver a recordar que, pese a la ideologización operada en la difusión de las doctrinas marxistas (que sirvió, tanto para justificar la excrecencia cultural del llamado "socialismo real", como para armar políticamente causas de nobleza incuestionable y avanzar en la conquista de los derechos sociales), ningún autor ha tenido en la historia de las ideas una influencia tan explosiva e inmediata como Karl Marx. Y que su idea más potente -esto es, que existe un futuro que proyectar, que hay grandes transformaciones que afectan a dimensiones cardinales de la vida social que merece la pena emprender- fue en el pasado, 
y habrá de serlo en el futuro, un freno para la barbarie y una esperanza para construir una sociedad más humana y justa'1.

Tampoco estaban para líricas los tiempos en que Herminio conformó su condición marxista. Nos lo recuerdan sus propias palabras, pronunciadas o escritas en diferentes textos y contextos, refiriendo su particular itinerario biográfico, su ambiente familiar, sus años de formación y de militancia política. Con respetuosa contundencia, con íntima convicción, evitando todo protagonismo, hablando en galego, sin cátedra, para los suyos, para quienes quisieran hacer el camino con él...

El camino del que yo quiero ahora esbozar algunos trazos es aquel que compartimos profesionalmente en cuanto profesores de Historia de la Educación que coincidieron en algunas experiencias similares; llegamos incluso a elaborar un texto ${ }^{2}$ que firmamos en común, obedeciendo, curiosamente, a la voluntad de otros: fueron algunos de sus alumnos o ex alumnos, sindicalistas de Comisiones Obreras de Enseñanza, y de mis alumnos o ex-alumnos (en ambos casos habría que hablar preferentemente en femenino) los que nos "juntaron" en esa empresa. Lo más sorprendente (y a la vez grato) fue constatar nuestra mutua ignorancia sobre el asunto, hasta muy avanzada la redacción del texto.

Conocí a Herminio Barreiro en octubre de 1982, con ocasión de la celebración del I Coloquio Nacional de Historia de la Educación, en Alcalá de Henares. Lo recuerdo bien: estaba entre el "grupo de gallegos", y tenía "buena pinta". Aquel Coloquio era la primera afirmación societaria de una Sección científica que, desde 1979, buscaba independizarse de la Sociedad Española de Pedagogía. En 1983 (con ocasión del Il Coloquio, celebrado en Valencia) aprobó sus primeros Estatutos, siendo en 1989, con Herminio ya integrado en su Junta Directiva, cuando se independizaría definitivamente como Sociedad Española de Historia de la Educación. De ella sería posteriormente vicepresidente, entre los años 1993 y 1997.

Aquel empeñado intento de la Sección de Historia de la Educación por desasirse de una rancia Sociedad Española de Pedagogía no obedecía (o lo hacía sólo secundariamente) a un "natural" proceso de replicación orgánica. Buscaba, creo, surgir como una criatura "nueva" en un país que quería ser "nuevo", construirse, todo él, de otra forma: como un país de países, de lenguas diversas, de biografías múltiples, un país cuya historia real (asfixiada bajo la Historia oficial) era necesario rescatar y nominar, tras la losa que la había ocultado largo tiempo. Por eso y para eso contó desde el primer momento con una poderosa energía de decenas de jóvenes investigadores que ella misma quería estimular y hacer confluir, buscando ocasiones de encuentro, organizándonos, apoyándonos, entusiasmándonos mutuamente. No creo equivocarme si afirmo que casi todos participábamos, entonces, de la idea de que aquel era un tiempo eminentemente colectivo y político, es decir, el tiempo, por fin, de la Historia (que nos ayudaría a comprendernos) y de la Educación (que

1 Véase la Introducción de Cesar Rendueles al texto K. Marx, El Capital. Antología, Madrid, Alianza editorial, 2010.

2 H. Barreiro y A. Terrón, La institución escolar: una creación del estado moderno, Barcelona, Octaedro-FIES, 2005. 
debía contribuir a cambiarnos). Y, entre nosotros, quizá ninguno tenía tan entrañada esa percepción como el propio Herminio.

De hecho él culminó por aquellos años (1982) su tesis sobre Lorenzo Luzuriaga, leída inmediatamente antes del Coloquio de Alcalá. $Y$ aunque en la década siguiente buena parte de nuestras investigaciones y tesis doctorales se dirigieron a desentrañar y construir una Historia de la Educación inserta en los marcos locales y regionales (confirmando en ellas que no había una España, sino múltiples, insistimos), nuestros focos nunca pudieron obviar (por más localistamente que se dirigieran) el potente núcleo analítico que él utilizó y construyó en la citada investigación. Un marco que incorporaba expresamente, combinándolas, la perspectivas sociológica e histórica como condicionantes esenciales del "hecho educativo"; que trataba de atender al juego dialéctico entre infraestructura material y superestructura ideológica en el que este "hecho" quedaba situado; que buscaba precisar la autonomía relativa (o no) de las teorías y las prácticas educativas... un marco, en resumen, que se correspondía con una determinada concepción de la Historia, que él reivindicaba expresamente (frente a la ideología de la desideologización) como componente intelectual inherente al oficio del historiador.

A la conformación de esa incipiente "nueva historiografía" educativa —que intentaba entonces buscar camino societariamente- Herminio aportó ya en 1985 sus propias "Consideraciones"3, desde las que nos ofrecía su punto de vista sobre los modelos historiográficos más pertinentes para nuestra disciplina, así como las nuevas vetas de investigación que habrían de abrirse en coherencia con el sentido por él atribuido a ese ámbito de conocimiento. Un sentido por cierto, tanto o más social que estrictamente académico e, incluso, científico. Paradójicamente, sin embargo, era justamente esa función social del conocimiento histórico ("la Historia está contribuyendo día a día a un mejor conocimiento de la educación actual y está posibilitando una intervención más eficaz en el sistema educativo") la que —nos recordaba - imponía rigurosas exigencias académicas y científicas: "debemos ser, pues, muy conscientes de la necesidad imperiosa de renovación curricular y metodológica de nuestra disciplina y arraigar la conciencia, en la docencia y la investigación, de la especificidad histórico-educativa en el ámbito de las ciencias de la educación". Que sus propuestas no fueron vanas en el interior de nuestro gremio lo prueba el hecho de que precisamente las vetas de renovación curricular por él entonces apuntadas (los procesos de escolarización, la "nueva historia" del currículo o la historia material de la enseñanza, entre otras) constituyeron los temas de diversos Coloquios nacionales en esos años y en los siguientes.

Cuando repaso, ahora, la asistencia de Herminio a tales Coloquios, a los que no faltó en ninguna de sus once primeras ediciones entre los años 1982-2001, presentando comunicaciones en todas ellas ${ }^{4}$, no puedo sino sorprenderme de su fidelidad a la SEDHE.

3 H. Barreiro, "Consideraciones en torno a la investigación histórico-educativa. Sobre objetivos y modelos", en Materiais pedagóxicos, Santiago, Universidade de Santiago de Compostela, 1985, págs. 9-14.

4 Todas ellas publicadas en las correspondientes Actas (excepto la primera, publicada en el volumen $n^{\circ} 2$ de Historia de la Educación): "Repercusiones de la revolución ideológica y científica del último tercio del siglo XIX 
Un término éste (fidelidad) que me parece más preciso que ningún otro para definir una relación que podría calificarse de eminentemente societaria, escasamente convencional y bastante alejada de los comportamientos típicamente profesionales. Su condición de profesor por encima de cualquier otra aspiración académica, su juego con la distancia corta y amistosa más que con el discurso largo y convencionalmente formalizado, su preferencia por el "pequeño grupo" para establecer los necesarios matices de los temas y de las ideas en los pasillos, hicieron de él un socio generoso, capaz siempre de aportar, de sumar, nunca de enconar o de tensar en las ineludibles discrepancias: fuese ello para colaborar a la difusión de la Sociedad, para organizar Coloquios o para contribuir al impulso de la Revista Historia de la Educación, creada en el año 1982 y en la que colaboró desde sus primeros números, 0 al de la serie Clásicos de Educación, en cuyo Consejo Asesor se integró desde su creación, a propuesta de la SEDHE, en $1998^{5}$.

De esa generosa actitud societaria podemos encontrar otras muestras, incluso cuando, paradójicamente, se manifestasen como ejercicios de expresa discrepancia con la producción de otros. Una actitud esta que, aunque "políticamente incorrecta" y, por ello, excepcional en la vida académica, es, creo, la auténtica esencia de lo que debe ser el sentido de una Sociedad científica. Entre ese tipo de ejercicios, recuerdo particularmente el que se concretó en su artículo "Nacional-catolicismo y educación en la España de la posguerra. Notas sobre una antología de textos y un estudio preliminar de A. Mayordomo"6. Que su punto de vista discrepase - seguramente más en la forma que en el fondo- del de su colega Mayordomo sobre la significación que éste atribuida al periodo franquista en la historia de la educación, era algo perfectamente lícito; que lo argumentase públicamente era, sin embargo, más excepcional. Discrepando de su valoración como período "importante por su particularidad" y "decisivo por sus consecuencias", Herminio afirmaba

en las innovaciones educativas de la ILE" (1982); "Las colaboraciones de Luzuriaga en El Sol, como agentes ideológicos de la escolarización en España (1917-1921)" (1983); "Condorcet/Quintana: un micromodelo de cotejo textual" (1984); "España ha dejado de ser católica': glosa de un discurso de Manuel Azaña sobre las relaciones Iglesia-estado en la II República" (1986); "Lorenzo Luzuriaga: Itinerario de un exilio. De Glasgow a Buenos Aires. Notas de prensa y correspondencia (1936-1959)" (1988); "Tres mujeres normalistas. Testimonio e interpretación de una experiencia en la Escuela Normal de Pontevedra (1954-1957)" (1990); "Ignacio de Loyola, entre Vives y Comenio. Notas marginales desde una visión generalista del siglo XVI" (1993); "Concepción Arenal y el educacionismo filantrópico" (1994); "De J.J Rousseau a Napoleón Bonaparte: política, ideología y primeras bases de los sistemas educativos contemporáneos" (1996); "Tres calas en las teorías de vanguardia sobre la educación superior en España: Giner de los Ríos, Ortega y Gasset, Carlos Lerena” (1998); "Pedagogía, educación social, educación popular...breves consideraciones sobre algunos programas docentes" (2001). En Coloquios posteriores: "José Castillejo (1877-1945) y el 'puente hacia Europa': de la creación de la junta de Ampliación de estudios al exilio: pequeña glosa sobre textos de David Castillejo, Irene Claramont y Rafael Martínez Nadal" (2007).

5 Herminio fue nombrado por la SEDHE para formar parte del Consejo Asesor desde el inicio de la Colección, en 1998; tras el acuerdo con la editorial Biblioteca Nueva comenzaron a salir las primeras publicaciones en 2001; fue responsable del estudio introductorio del segundo volumen editado en la serie (La Escuela única, de Lorenzo Luzuriaga). Gabriela Ossenbach recuerda sus propuestas de clásicos a reeditar, entre los que se incluían Cossio, Helvetius, Condorcet, los Cuadernos de Quejas de la Revolución francesa, Buisson, Bertand Russell y una propuesta curiosa: Jules Vallés: El niño, el bachiller, el insurrecto.

6 En Historia de la Educación, vol. XIV-XV, 1995-96, págs. 417-432. 
rotunda y apasionadamente su inanidad e intranscendencia: “...muy al contrario, a medida que pasa el tiempo, el franquismo se va empequeñeciendo más y más y se está convirtiendo en una minúscula y patética anécdota histórica que no aportará nada "importante" ni "decisivo" a la historia contemporánea de nuestros pueblos. Eso sí, fue capaz de ahogar nuestra andadura colectiva durante más de cuarenta años; fue capaz de sembrar el oscurantismo y la muerte durante todo ese tiempo, fue capaz de lastar la conciencia social de una época. Pero, sobre todo eso, cada vez queda menos. Y algún día, muy probablemente no quedará nada. Estamos asistiendo ya a los últimos ramalazos esperpénticos de una herencia miserable". Pero más allá de la discrepancia, lo que queda "en pie", lo que esta diatriba aireada en público aportó fueron, básicamente, dos consideraciones societariamente importantes: primero, que la crítica es una actividad obligada en la vida científica, perfectamente compatible con el reconocimiento: "el trabajo de Mayordomo es un trabajo necesario. Y la antología de textos y documentos que nos presenta es un elemento esclarecedor y desmitificador de una ideología que quiso ser dominante pero que no lo consiguio"; y segundo: que los historiadores tienen el derecho y el deber de hacer historia "de la mismísima actualidad", sin refugiarse en la llamada "perspectiva histórica", una práctica interesada, una forma de convertir el pasado en algo inerte.

Lo cierto es que aquella contundente reclamación a rechazar una utilitarista concepción de la llamada "perspectiva histórica" - "mecanismo, como se sabe, propalado por el sistema establecido para perpetuarse. Manera de conseguir que el tiempo pudra la situación y la vuelva irreconocible. Intento de impedir la claridad y confundir la memoria colectiva, de convencer a la gente de que un día vivió lo que no vivió, contempló lo que no contempló y sintió lo que no sintió. Forma, en suma, de adueñarse del pasado para hacer ver que un día fue lo que no fue"- encontró cauce en nuestro gremio: multitud de investigaciones sobre aspectos concretos de la política franquista (especialmente las referidas a depuración del profesorado) fueron "rompiendo el viejo corsé, y denunciando, una por una, todas las barbaridades cometidas, todos los ultrajes sufridos, todas las vidas e ilusiones cercenadas", mientras que otras muchas (aquellas que desentrañaron el sistemáticamente ocultado período republicano) vinieron a constatar lo que él entonces afirmaba: que "los hombres y las situaciones pasan, pero las ideas permanecen" y que "el esplendor de los años republicanos seguía fluyendo como un río subterráneo por debajo de todos nosotros".

\section{Los "temas" de su "producción"}

El entrecomillado que pongo a estos dos términos pretende subrayar el escaso sentido literal con que debe tomarse, en esta particular ocasión, lo que constituye un epígrafe obligado en toda revisión sobre la obra académica de un profesor-investigador. Es difícil precisar convencionalmente los "temas" elegidos sobre los que "producir" resultados, en este caso en términos de "sanción histórica", cuando nos referimos a alguien para quien los temas (el tema) por el que se interesaba se enunciaba complejamente, sin "desvitalizarlo ni desmenuzarlo", atendiendo a un criterio de partida - "la educación, los sistemas

7 Ibid. p. 420 
educativos, juegan un papel crucial en el desarrollo de la Historia y tienen, por tanto, una participación destacada en la dinámica de las sociedades humanas"- del que se hace derivar un propósito analítico preciso: "es pues, necesario, aquilatar la incidencia de la Historia de la Educación en la Historia de la Humanidad y definir en términos de historia cualitativa el sentido de la lucha ideológica de clases en el interior mismo del sistema educativo. Algo que sería imposible hacer sin el descubrimiento científico del papel de la historia realizado por Karl Marx y sin su aportación cardinal como fundador de la ciencia de las sociedades humanas"8.

Si la educación ha jugado un papel crucial en el desarrollo de las sociedades humanas, tal papel fue excepcionalmente importante en el marco político que acompañó la revolución ideológica y científica de la segunda mitad del siglo XIX, una revolución tan determinante en la historia de la humanidad (con la instauración hegemónica del modo de producción del capitalismo industrial) que alumbraría "la vasta complejidad del mundo contemporáneo". En ese marco, las relaciones entre educación y política, que, bajo el enunciado de "educación pública" habrían sido ya teorizadas en la Grecia clásica — "con Platón empieza todo", afirma - y elaboradas "textualmente" por los protagonistas intelectuales de la Revolución francesa (los Cahiers de Doleances, los Rapports, los escritos de Condorcet...), cobrarán vida institucional y "práctica" con la puesta en pie de los sistemas educativos nacionales en la Europa de la segunda mitad del XIX: las conexiones entre educación y política que establece el nuevo orden burgués dejarán desde entonces de enunciarse eufemísticamente, al punto de que nuestro Gil de Zárate llegará a afirmar descarnadamente: "la cuestión de la enseñanza es cuestión de poder: el que enseña domina". Algo claramente comprendido por los grupos contrahegemónicos, que en las décadas siguientes problematizarán una escuela sobre la que irán proyectando concepciones políticas que complejizan una visión unitaria sobre la misma: escuela confesional versus escuela laica; escuela privada versus escuela pública y escuela neutra versus escuela de clase.

Esta "lectura" sobre la significatividad atribuida a las transformaciones sociales, económicas, culturales y científicas que se operan en ese tiempo, con análisis deudores de K. Marx y, en general, de la historiografía y la sociología predominantemente marxista (Suchodolski, Gramsci, Hobsbawn, Althusser, Bordieu y Passeron, Lerena...) sitúan "el tema" de Herminio, tanto en lo relativo a los márgenes temporales como en la selección del "sujeto" (individual, pero necesariamente colectivo) que podría encarnar en nuestro país esa coyuntura histórica: tal sería Lorenzo Luzuriaga, quien "dedicó la mayor parte de su trabajo a la armonización de la enseñanza con la renovación de estructuras que se intentaba en los restantes aparatos del viejo Estado y en otros órdenes de la vida nacional. Es pues, el suyo, un buen ejemplo para tal propósito, tanto por el sentido de su dedicación profesional como por su carácter de personaje-puente entre el inicio de ese proceso (que Herminio sitúa en el Sexenio, cuando "arraiga la idea de la necesaria alianza entre política y educación") y su culminación, en el período de la II República". Esta afirmación, que sostiene en la Introducción de su tesis doctoral, dará cuenta del sentido con que acomete

8 H. Barreiro, Consideraciones..., pág. 13 
una investigación que busca analizar de manera exhaustiva, específica y ejemplificadora, un "problema" esencial desde el que percibir la mecánica de la lucha de clases inserta en un sistema educativo entendido como "aparato de estado".

La historiografía y la sociología en la que se apoya (marxista predominantemente, pero no encorsetada en las ideologizaciones-cliché que durante décadas limitaron su potencia analítica), le permitieron percibir algo que ya Marx había dejado meridianamente claro: que la enseñanza general obligatoria, pública y gratuita era una aspiración revolucionaria; que la enseñanza puede ser estatal sin quedar necesariamente bajo el control de gobierno; y que es necesario eliminar todo aplazamiento pesimista que plantee renunciar a intervenir en este sector (el de la educación) hasta la previa transformación de las estructuras sociales ${ }^{9}$. Es decir, que la educación - actividad eminentemente política - guarda con "la política" una relación no unívoca sino dialéctica, en cuanto dotada de un inequívoco margen de autonomía y de capacidad transformadora. Herminio, que indaga sobre ese margen de autonomía en diversos trabajos (por ejemplo, en la Introducción crítica a la reedición de la obra de Luzuriaga Pedagogía social y política, en la que se pregunta: “...porque ¿hasta donde van unidas y donde deben separase - si es que deben-educación, cultura y política?'), no parece tener dudas sobre la respuesta, una respuesta coherente, por otra parte, con su propio oficio. Así, cuando prologa la edición castellana de la obra de Freinet hecha por Morata, afirma, identificándose tácitamente con el autor: "acción pedagógica, la de Freinet, que se encamina siempre a la acción política. Pero sin mezclar las cosas. Preservando siempre la autonomía -que él sabe relativa- de lo pedagógico, del valor en sí de la acción educativa. Terreno difícil y movedizo que, como se sabe, acarreará la crítica de los políticos doctrinarios y de los sociólogos radicales, para los que el elemento reproductor es el elemento dominante y casi único"10. Por si cabía alguna duda de su confianza en ese papel liberador (y no meramente reproductor) de la educación, reproduzcamos de nuevo sus precisas palabras, con todo su brillo:

"Pero la educación es mucho más que eso. La educación es —por lo menos desde los tiempos de Condorcet- uno de los derechos fundamentales de la humanidad y, por supuesto, uno de los derechos fundamentales de nuestro tiempo. Un derecho que es contribución importantísima en el camino hacia una sociedad más justa e igualitaria. Y es también hoy garantía de defensa de las diferencias de atributos entre hombres y mujeres, pero también de la igualdad social más irrenunciable entre unos y otras. Sigue siendo, además, la educación, elemento fundamental para la transformación del mundo y para la conquista de la libertad. Y, por supuesto, para todos los que vivimos y trabajamos cada día en su entorno, será siempre una pasión irrefrenable, una emoción permanente y un sentimiento gratificante al máximo"11.

9 M. A. Manacorda, Marx y la pedagogía moderna, Barcelona, Oikos-Tau, 1969.

10 C. Freinet, La escuela moderna francesa. Una pedagogía moderna de sentido común. Las invariantes pedagógicas, Madrid, Morata, 1996, pág. 13.

11 H. Barreiro, La institución escolar..., pags. 17-18. 


\section{Epílogo}

Cuando reviso su obra no me cabe duda de que Herminio construyó sus preocupaciones intelectuales al hilo de su propia socio-biografía: intentando entender aquello que le duele (Recordar doe) y construir aquello que le hace concebir esperanza, un dolor y una esperanza que sabe no personal e intransferible, sino encastradas ambas en la dinámica social y en el "tiempo largo". Haciendo un ejercicio — seguramente excesivo- de empatía, me atrevo a insertar sus preocupaciones intelectuales en un estado vital y emocional que ha recreado espléndidamente Antonio Muñoz Molina en su novela El jinete polaco: en ella da cuenta emocionada de los contradictorios, confusos y culpabilizados sentimientos de aquellos jóvenes que, en los años sesenta, se iban (nos íbamos) a "estudiar una carrera", arrostrando al hacerlo la sensación de estar desertando de un mundo al que estaban naturalmente abocados, un mundo de hombres y mujeres cuya vida de trabajo, de pobreza y de miedo les mantenía en el estupor propio de los seres inocentes (esos "santos inocentes" de los que nos habla Delibes). Quizá por eso Herminio se aplicó a "averiguar" y a "entender", para finalmente "comprender", dando así sentido a su transformación intelectual y al inevitable extrañamiento con los suyos que acompaña a ese proceso (ese extrañamiento que Narciso de Gabriel dice percibir físicamente cuando su actividad como investigador le conduce a retornar de nuevo al que fuera el territorio de su infancia). Y quizá también por eso se volcase en la enseñanza, haciendo suya aquella afirmación tan institucionista de Rodolfo Llopis según la cual revolución y educación (revolución y pedagogía) constituyen tareas prácticas indisociables.

"Averiguar, investigar, enseñar, aprender... Averiguar para investigar. Investigar para enseñar. Enseñar para aprender. Aprender a aprender...". Esta secuencia, que encabeza uno de sus artículos sobre el comentario de textos como recurso didáctico para la Historia de la Educación ${ }^{12}$, no constituye, en absoluto, un ingenioso juego de palabras; es una construcción sólidamente reflexionada que expresa de manera manifiesta el modo de entender y ejercer su oficio —también en su componente didáctico- por alguien empeñado en que sus alumnos no solo "aprendieran", sino que, al hacerlo, como él y con él, averiguaran y entendieran.

Quiero concluir con una última consideración, de nuevo literaria, sobre su forma de estar en el mundo y, concretamente, en la Sociedad científica que compartimos durante muchos años. Una forma de estar (y de ser) tan netamente cordial y solidaria que pareciera estar directamente insuflada en su espíritu por el machadiano maestro Mairena cuando conmina a sus discípulos con el viejo proverbio castellano: "Sed modestos. Nadie es más que nadie. Esto quiere decir cuánto es difícil aventajarse a todos, porque por mucho que un hombre valga, nunca tendrá valor más alto que el de ser hombre".

12 Incluido en el volumen coordinado por Narciso de Gabriel y Antonio Viñao, La investigación histórico-educativa. Tendencias actuales, Barcelona, Ronsel, 1997, págs. 241-254. 